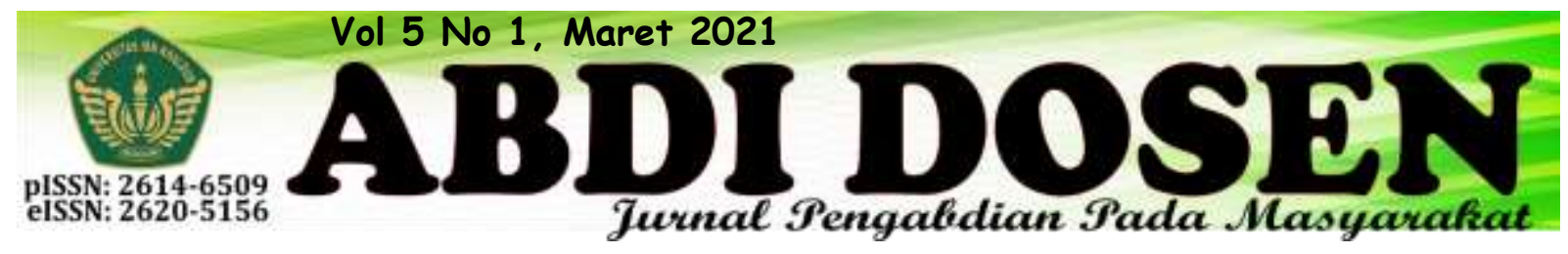

\title{
PEMBERDAYAAN MASYARAKAT DESA BANYU RESMI DALAM MENINGKATKAN KUALITAS HIDUP MELALUI BIDANG PENDIDIKAN, KESEHATAN DAN EKONOMI
}

\author{
Fitria Rachmawati ${ }^{1}$, Mohamad Sahril ${ }^{2}$, Paqih Baihaqi, Sinta ${ }^{3}$ \\ fitria@uika-bogor.ac.id ${ }^{1}$ \\ msahril@uika-bogor.ac.id ${ }^{2}$ \\ sinta@gmail.com ${ }^{3}$
}

Fakultas Teknik dan Sains Universitas Ibn Khaldun ${ }^{1}$, Fakultas Keguruan dan Ilmu Pendidikan Universitas Ibn Khaldun², Mahasiswa KKN Kelompok 41\&42 Tahun 2019³

\begin{abstract}
ABSTRAK
Pembahasan terkait dengan tujuan pemberdayaan, Sulistiyani (2004) menjelaskan bahwa tujuan yang ingin dicapai dari pemberdayaan masyarakat adalah untuk membentuk individu dan masyarakat menjadi mandiri. Kemandirian tersebut meliputi kemandirian berpikir, bertindak dan mengendalikan apa yang mereka lakukan. Perlunya upaya pemberdayaan adalah berangkat dari kenyataan masih lemahnya posisi sebagian besar masyarakat dalam menuntut hak dan menjalankan kewajibannya ditunjukkan dengan kurang aksesnya mereka terhadap beberapa fasilitas, misalnya informasi, teknologi, permodalan usaha, hukum, dan kesehatan Berbagai kelemahan akses tersebut diawali dengan rendahnya tingkat pendidikan yang dimiliki oleh masyarakat kita terutama di pedesaaan yang ada di Kp Kenanga RT 04/06, Desa Banyu Resmi, Kec. Cigudeg, Kab. Bogor. Pelaksanaannya dalam masyarakat ataupun sekolah di wujudkan dengan pelatihan skill, mengajar dan tak lupa pentingnnya menanamkan akhlaqul karimah merupakan pondasi terpenting dalam segala aspek kehidupan. Dari semua pencapaian tersebut akan tercapaianya kualitas hidup yang diharapkan oleh semua masyarakat.
\end{abstract}

Kata kunci: Pemberdayaan, Masyarakat, Kualitas Hidup.

\section{PENDAHULUAN}

Desa Banyu Resmi adalah salah satu Desa di Kecamatan Cigudeg Kabupaten Bogor yang mempunyai luas wilayah 23,115,4 ha. Jumlah penduduk Desa Banyu Resmi sebanyak 6.097 jiwa yang terdiri dari 3.206 laki - laki dan 2.891 perempuan, dengan jumlah kepala keluarga sebanyak $1.745 \mathrm{kk}$, sedangkan jumlah keluarga miskin (gakin) $610 \mathrm{kk}$ dengan presentase $35 \%$ dari jumlah keluarga yang ada di Desa Banyu Resmi Kecamatan Cigudeg.

Batas - batas administrarive Pemerintah Desa Banyu Resmi Kecamatan
Cigudeg Kabupaten Bogor adalah sebagai berikut :

\begin{tabular}{|l|l|l|}
\hline No & Keterangan & Berbatasan \\
\hline 1. & Sebelah utara & Desa Banyuasih \\
\hline 2. & Sebelah timur & $\begin{array}{l}\text { Desa Leuwi } \\
\text { Batu }\end{array}$ \\
\hline 3. & Sebelah selatan & Desa Kalong \\
\hline 4. & Sebelah barat & Banyu Wangi \\
\hline \multicolumn{3}{|c|}{ Dilihat dari topografi dan kontur } \\
tanah Desa Banyu Resmi Kecamatan
\end{tabular}

Cigudeg secara umum berupa hutan yang berada pada ketinggian antara $500 \mathrm{M}$ s/d 
700M diatas permukaan laut. Desa banyuresmi terdiri dari 7 (tujuh) dusun, 14 (empat belas) RW dan 35 (tiga puluh lima) RT orbitasi dan waktu tempuh dari Ibu Kota Kecamatan $8 \mathrm{~km}$ dengan waktu tempuh 45 menit dari ibu Kota Kabupaten 62 km dengan waktu tempuh 4 jam.

\section{Mata Pencaharian}

\begin{tabular}{|l|l|l|}
\hline No & \multicolumn{1}{|c|}{ Profesi } & \multicolumn{1}{|c|}{ Jumlah } \\
\hline 1. & Petani & 110 orang \\
\hline 2. & Dagang & 70 orang \\
\hline 3. & PNS & 4 orang \\
\hline 4. & TNI/Polri & 0 \\
\hline 5. & Pegawai/Karyawan & 115 orang \\
\hline 6. & Buruh & 1545 orang \\
\hline 7. & Jawa & 3 orang \\
\hline 8. & Pensiunan & 3 orang \\
\hline 9. & Montir & 5 orang \\
\hline 10. & Peternak & 3 orang \\
\hline
\end{tabular}

\section{Sarana Pendidikan}

\begin{tabular}{|l|l|l|}
\hline No & \multicolumn{1}{|c|}{$\begin{array}{c}\text { Sarana } \\
\text { Pendidikan }\end{array}$} & \multicolumn{1}{|c|}{ Jumlah } \\
\hline 1. & TK/MD & 3 unit \\
\hline 2. & SD Negeri & 4 unit \\
\hline 3. & $\begin{array}{l}\text { Madrasah } \\
\text { Ibtidaiyah }\end{array}$ & 1 unit \\
\hline
\end{tabular}

Sarana Kesehatan

\begin{tabular}{|l|l|l|}
\hline No & \multicolumn{1}{|c|}{$\begin{array}{c}\text { Sarana } \\
\text { Kesehatan }\end{array}$} & \multicolumn{1}{|c|}{ Jumlah } \\
\hline 1. & Bidan Desa & 2 orang \\
\hline 2. & Dukun Beranak & 7 orang \\
\hline 3. & $\begin{array}{l}\text { Kader } \\
\text { Posyandu }\end{array}$ & 10 orang \\
\hline 4. & Posyandu & 10 orang \\
\hline 5. & Klinik & 1 orang \\
\hline 6. & Pos KB & 1 orang \\
\hline
\end{tabular}

\section{Sarana dan Prasarana}

\begin{tabular}{|c|c|c|}
\hline No & $\begin{array}{l}\text { Sarana \& } \\
\text { Prasarana }\end{array}$ & Jumlah \\
\hline 1. & Kios/Toko/Warung & 30 unit \\
\hline 2. & $\begin{array}{l}\text { Material/Rentang } \\
\text { Kayu }\end{array}$ & 3 buah \\
\hline 3. & $\begin{array}{l}\text { Pertenakan Ayam } \\
\text { Ras }\end{array}$ & 7 unit \\
\hline 4. & Isi ulang air & 1 unit \\
\hline
\end{tabular}

tahun 2004, Pemerintah Desa adalah penyelenggara urusan Pemerintah, oleh Pemerintah Desa dan BPd dalam mengatur dan mengurus kepentingan masyarakat setempat berdasarkan asal usul dan adat istiadat setempat, yang diakui dan dihormati dalam sistem pemerintahan NKRI. Urusan Pemerintah yang menjadi kewenangan Kabupaten atau Kota yang diserahkan pengaturannya kepada Desa adalah urusan pemerintahan yang secara langsung dapat meningkatkan pelayanan dan pemberdayaan masyarakat. 


\section{METODE PENGABDIAN}

Pelaksanaan KKN di Desa Banyu Resmi Kp. Kenanga RT 4 RW 6 ini terhitung selama 6 Agustus - 5 September 2019 dengan tahapan pelaksanaan dengan hitungan permingggu. Adapun tahapan pelaksanaan sebagai Tahapan pelaksanaanan berikut:

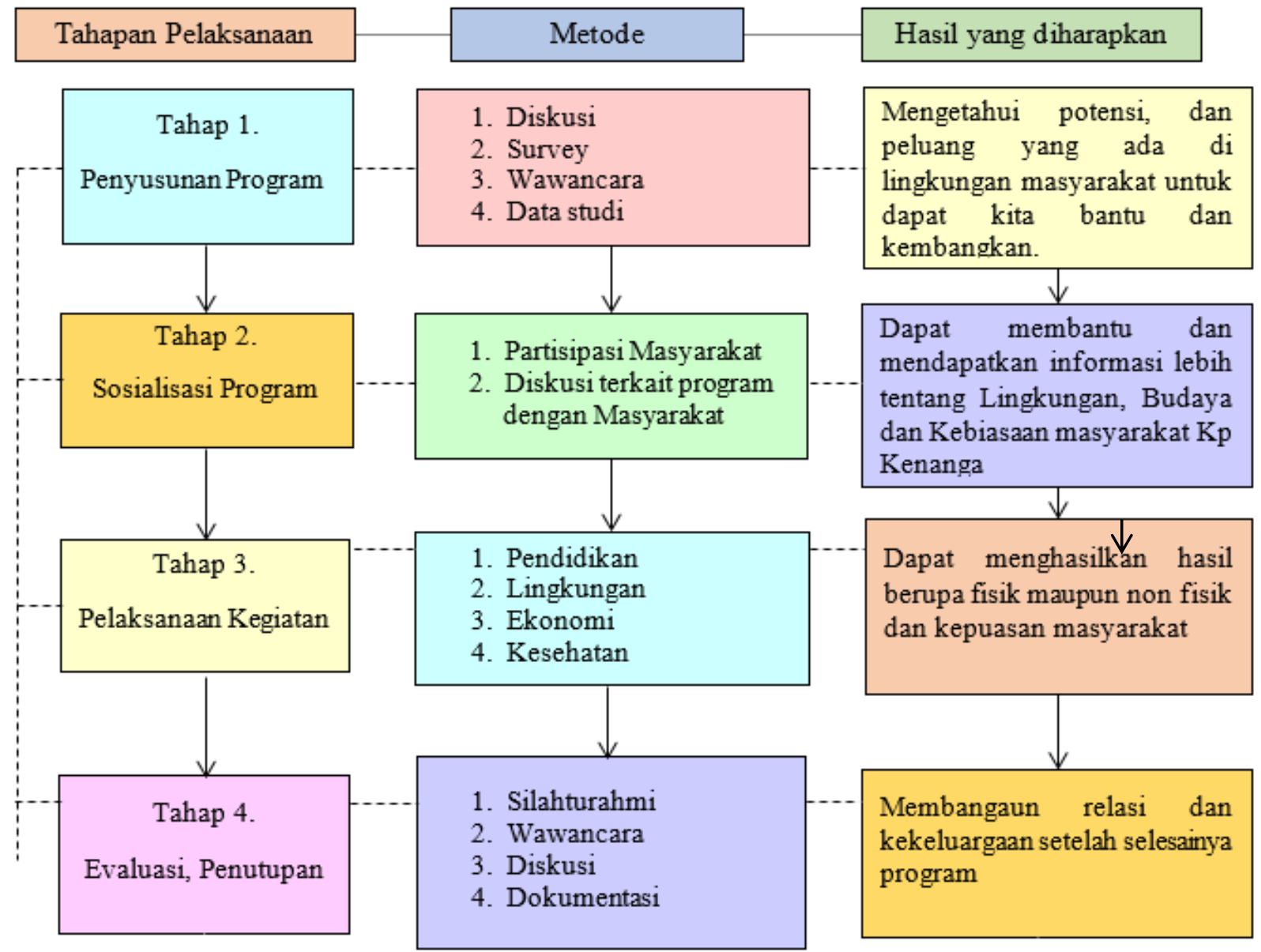

\section{Jadwal Kegiatan}

\begin{tabular}{|c|l|c|c|c|c|}
\hline \multirow{2}{*}{ No. } & \multicolumn{1}{|c|}{ Kegiatan } & \multicolumn{3}{c|}{ Minggu } \\
\cline { 3 - 5 } & \multicolumn{1}{|c|}{$\mathbf{1}$} & $\mathbf{2}$ & $\mathbf{3}$ & $\mathbf{4}$ \\
\hline 1 & Penyusunan Rencana Kegiatan & & & & \\
\hline 2 & Sosialisasi Rencana Kegiatan & & & \\
\hline 3 & Silaturahmi Tokoh dan Masyarakat & & & \\
\hline 4 & Mengajar Ngaji & & & & \\
\hline 5 & Pengajian Rutin bersama warga & & & & \\
\hline 6 & Pengajian Yasinan & & & \\
\hline 7 & $\begin{array}{l}\text { Pengajaran Di SD Banyu Resmi 01 dan MI } \\
\text { Nurul Huda }\end{array}$ & & & \\
\hline
\end{tabular}




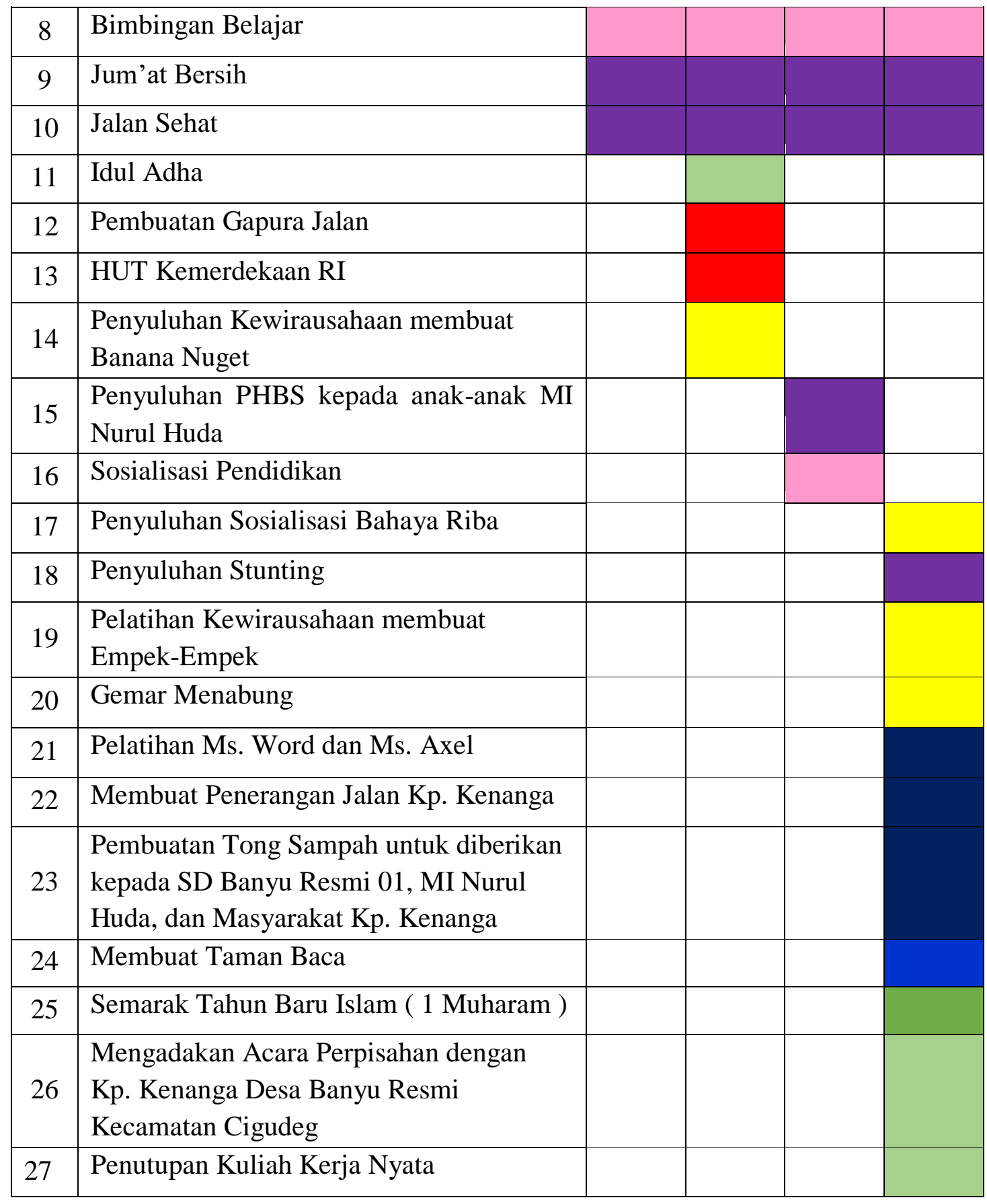

\section{Metode Pendekatan}

Dalam melaksanakan penelitian ini kami menggunakan beberapa pendekatan yang strategis, diantaranya:

1. Pendekatan berdasarkan karakter masyarakat, yaitu pembinaan yang dilakukan akan disesuaikan dengan karakter masyarakat, dapat membantu mereka pada hal-hal positif yang dapat membantu mereka dalam ruang lingkup pendidikan, kesehatan, ekonomi dan lingkungan. Hal ini dilakukan untuk memberi pengalaman yang nyata kepada masyarakat tentang sesuatu yang dilakukan atau dirasakan oleh orang lain.

2. Pendekatan Organisasi, yakni pendekatan terhadap para jajaran lembaga masyarakat, lembaga pendidikan pemuda-pemudi, ibu-ibu Majelis yang ada di Kp. Kenanga Desa Banyu Resmi. 
3. Pendekatan Kekerabatan, yakni pengarahan atau pembinaan yang sudah dilakukan senantiasa dikaitkan hanya untuk membangun kekerabatan dengan warga Desa Banyu Resmi, khususnya Kp. Kenanga.

Dalam pelaksaanya, untuk mengetahui bagaimana langkah yang perlu ditempuh dalam memperoleh atau mengimpulkan data yaitu dengan menggunakan metode wawancara dengan para tokoh agama setempat, instansi desa dan masyarakat sekitar.

Selain itu, kami juga menggunakan metode pengumpulan data kualitatif sejumlah besar fakta dan data tersimpan dalam bahan yang berbentuk dokumentasi. Data biasa berbentuk surat, catatan harian, arsip foto, hasil rapat, jurnal kegiatan dan lain sebagainya.

\section{Partisipasi Masyarakat}

Partisipasi masyarakat yang dapat dilakukan dalam kegiatan ini adalah :

1. Bersedia untuk diwawancarai terkait sosialisasi program yang ditawarkan.

2. Kepala Desa dan Staff membantu mencari tempat hunian selama KKN

3. Kepala Desa dan Stuff membantu merekomendasikan untuk kita mengajar di SD dan MI yang ada di Desa Banyu Resmi

4. Masyarakat bersedia mengikuti penyuluhan serta berpartisipasi dalam program-program yang melibatkan massa

5. Mengizinkan untuk membantu mengajar mengaji di Majelis dan mendukung anak-anak untuk mengikuti Bimbingan Belajar.
6. Mengizinkan mahasiswa untuk ikut serta dalam perayaan Hari Idul Adha dengan warga Kp. Kenanga.

7. Bersama pemuda, membantu menyusun lomba dalam kegiatan memperingati Hari Kemerdekaan

8. Warga membantu dalam memeriahkan peringatan Tahun Baru Islam yang dibarengi dengan acara Penutupan KKN di Kp. Kenanaga Desa bayu Resmi yang dipenuhi dengan kesederhanaan dan nuansa Islami

\section{Langkah Evaluasi}

Evaluasi yang akan dilakukan adalah terdiri dari :

1. Evaluasi Masukan meliputi pertimbangan tentang sumber dan strategi yang diperlukan untuk mencapai tujuan terlaksananya program. Informasi-informasi yang terkumpul selama tahap penilaian hendaknya dapat digunakan untuk menentukan sumber dan strategi didalam keterbatasan dan hambatan yang ada.

2. Evaluasi proses, yang terkait dengan perencanaan, pelaksanaan dan monitoring kegiatan. Evaluasi proses akan dilakukan setiap pekan bersama dengan seluruh anggota KKN TT kelompok 41 dan 42.

3. Evaluasi Hasil penilaian dalam mengukur keberhasilan pencapaian program bersifat fisik maupun non fisik, penilaian tersebut dikembangkan dan diadmistrasikan. Sehingga data yang dihasilkan sangat berguna bagi anggota dan masyarakat setempat dalam menentukan apakah program, diteruskan, dimodivikasi atau dihentikan. 


\section{REALISASI PROGRAM}

Realisasi Program KKN TT 2019

dilaksanakan selama kurang lebih 30 hari terhitung sejak tanggal 6 Agustus sampai 5 September 2019. Berikut ini adalah laporan berbagai kegiatan yang telah dilaksanakan oleh mahasiswa KKN TT kelompok 41 dan 42 di Desa Banyu Resmi, Kecamatan Cigudeg, Kabupaten Bogor. Berikut program-program kerja yang telah dilaksanakan yaitu :

\section{Program Bidang Pendidikan}

a. Bimbingan Belajar

Kegiatan Bimbingan Belajar ini bertujuan untuk memberikan pengajaran kepada anak-anak Kp. Kenanga Desa Banyu Resmi mengenai Bahasa Inggris dan Bahasa Arab.

b. Pengajaran di Sekolah Dasar dan Madrasah Ibtidaiyah

Untuk kegiatan ini kami di beri kesempatan untuk mengajar di dua sekolah yaitu di SD Banyu Resmi 01 dan MI Nurul Huda. Adapun tujuan dari program ini yaitu untuk membantu guru-guru disekolah dalam hal pemberian mata pelajaran karena kekurangannya tenaga pengajar, sehingga para mahasiswa juga dapat berkesempatan mengimplementasikan ilmu dan pengetahuan yang telah di peroleh dalam perkuliahan kepada ana-anak yang bersekolah di SD dan MI tersebut.

c. Membuat Taman Baca

Berbagi buku, berbagi ilmu untuk membangun generasi muda yang berkualitas dengan membuka taman baca di Majelis Ta'lim Al Barokah yang bisa berguna dan bermanfaat bagi anak-anak Kp. Kenanga Desa Banyu Resmi.

\section{Program Bidang Ekonomi}

a. Penyuluhan Kewirausahaan membuat Banana Nugget dan Empek-Empek Penyuluhan kewirausahaan ini bertujuan untuk membantu meningkatkan perekonomian masyarakat Kp. Kenanga Desa Banyu Resmi khususnya ibu rumah tangga dengan memberikan pengetahuan serta pemahaman mengenai apa itu wirausaha dan bagaimana cara membuka sebuah peluang usaha. Kami memberi contoh dari hal-hal yang simple, mudah, dan murah yaitu dengan bermodalkan buah pisang yang bisa diberi sedikit inovasi untuk dijadikan makanan yang kekinian, selain itu kami juga memberi contoh pembuatan empek-empek yang isiannya kita ganti dengan tahu.

b. Gemar Menabung

Kegiatan ini sebagai edukasi dan motivasi kepada anak-anak untuk menanamkan sifat gemar menabung sejak dini karena menabung dapat memberikan dampak positif dimasa yang akan datang. Oleh karena itu, dalam kegiatan ini anak-anak diajarkan untuk menyisihkan sedikit uang jajannya untuk ditabung ke dalam celengan.

c. Penyuluhan Sosialisasi Bahaya Riba Program penyuluhan Ekonomi Syariah dengan tema Bermuamalah Secara Islami ini bertujuan untuk memberikan pemahaman kepada masyarakat pentingnya menerapkan nilai-nilai syariat Islam dalam bermuamalah. Serta hal-hal yang dilarang dalam 
muamalah terutama riba dan prakteknya terutama pada pinjaman berbunga yang ada di masyarakat.

\section{Program Bidang Kesehatan}

a. Jumat bersih

Kegiatan ini dilakukan dengan tujuan untuk menjadikan Kp. Kenanga Desa Banyu Resmi menjadi kampung yang bersih dan sehat. Dilakukan secara rutin satu minggu sekali yaitu pada hari Jum'at. Mahasiswa dibantu masyarakat untuk merealisasikan tujuan dari kegiatan ini.

b. Senam dan Jalan Sehat

Kegiatan ini dilakukan mahasiswa bersama anak-anak Kp. Kenanga Desa Banyu Resmi setiap hari Minggu pagi. Adanya kegiatan ini bertujuan untuk meningkatkan kesehatan anak-anak serta salah satu upaya pendekatan mahasiswa kepada masyarakat.

c. Penyuluhan PHBS

Pelatihan perilaku hidup bersih dan sehat merupakan salah satu cara sederhana dalam upaya peningkatan kesehatan masyarakat yang ada di Desa Banyu Resmi. Walaupun pelatihan perilaku hidup bersih dan sehat ini dilakukan secara sederhana, namun setidaknya dapat menimbulkan kesadaran pada masyarakat tentang hal-hal kecil yang dapat berpengaruh terhadap kesehatan mereka.

\section{d. Penyuluhan Stunting}

Kegiatan ini dilakukan karena adanya kejadian stunting di Desa Banyu Resmi, maka dari itu para mahasiswa melakukan Penyuluhan tentang Stunting, yang bertujuan untuk memberikan informasi kepada masyarakat khususnya ibu hamil dan ibu yang memiliki balita di Kp. Kenanga Desa Banyu Resmi agar mereka bisa mencegah terjadinya kejadian stunting. Diantaranya memberikan informasi tentang asi ekslusif, MPASI, makanan bergizi serta menjaga kebersihan sekitar lingkungan nya.

\section{Program Bidang Teknik}

a. Pelatihan Microsoft Word dan Microsoft Excel

Pelatihan ini bertujuan untuk membantu masyarakat khususnya pemuda-pemuda Kp. Kenanga Desa Banyu Resmi dalam belajar mengetik dan memasukan data di komputer atau laptop. Pelatihan ini penting karena zaman sudah modern, pemahaman mengenai Ms. Word dan Ms. Excel bisa membantu warga apabila suatu waktu terdapat agenda yang membutuhkan keterampilan tersebut.

b. Membuat Penerangan Jalan

$$
\text { Dilihat dari keadaan }
$$
sepanjang jalan menuju Kp. Kenanga Desa Banyu Resmi yang tidak terdapat penerangan jalan, maka kami mahasiswa berinisiatif untuk membuat penerangan jalan guna membantu memudahkan masyarakat setempat dalam kenyamanan beraktifitas khusunya pada malam hari.

c. Pembuatan Tong Sampah

Pembuatan tong sampah ini bertujuan untuk membantu masyarakat dalam menjaga kebersihan lingkungan agar tetap bersih dari sampah dan sekaligus sebagai kenang-kenangan dari mahasiswa KKN UIKA 2019 kelompok 41 dan 42 untuk masyarakat Desa Banyu Resmi. 
5. Program Bidang Agama Islam

a. Pengajian Rutin warga

Dalam kegiatan ini selain meningkatkan keagamaan masyarakat juga menjadi alat silaturahmi mahasiswa dengan masyarakat yang ada di Kp. Kenanga Desa Banyu Resmi karena di pengajian rutin ini hampir seluruh masyarakat yang ada, ikut serta dalam kegiatan tersebut.

b. Pengajaran Tahsin

Kegiatan mengajar tahsin atau mengaji di Kp. Kenanga Desa Banyu Resmi ini dilaksanakan untuk membantu tokoh masyarakat dalam memberikan pengetahuan keagamaan sejak usia dini. Selain itu pelaksanaan mengajar ngaji ini juga bertujuan untuk memotivasi anak-anak agar rajin mengaji guna mendapatkan bekal dunia dan akhirat.

c. Pengajian Yasinan

Kegiatan ini dilakukan secara rutin setiap malam Jum'at untuk pengajian anak-anak bersama para Mahasiswa dipimpin langsung oleh Mahasiswa mulai dari baca tahlil doa dan kajian kitab Ar Rohiq Al Mahktum karya syekh Syaifurrahman Al Mubarakfury tentang siroh nabawiyah di posko KKN Kp. Kenanga Desa Banyu Resmi.

d. Memperingati Tahun Baru Islam (Semarak 1 Muharam)

Semarak 1 Muharam adalah kegiatan perayaan tahun baru Islam.
Kegiatan ini berisi lomba-lomba Islami untuk anak-anak pengajian Majelis Taklim Al-Barokah Kp. Kenanga, Desa Banyuresmi yang di adakan pada tanggal 1-3 September 2019, kemudian dilanjutkan dengan pengajian Akbar sekaligus santunan anak yatim dan jompo, penyerahan hadiah dan penutupan kegiatan KKN TT kelompok 41 dan 42. Kegiatan ini bertujuan untuk meningkatkan semangat anak-anak dalam mempelajari Agama Islam serta menanamkan nila-nilai hijrah Rasulullah Saw kepada masyarakat.

\section{Program Tambahan}

a. Merayakan HUT RI ke 74

Kegiatan ini dilakukan untuk merayakan HUT RI yang ke 74 dan untuk meningkatkan rasa semangat patriotisme dan nasionalisme masyarakat terhadap Negara Kesatuan Republik Indonesia. Selain itu, tujuan dari kegiatan ini juga yaitu untuk menumbuhkan rasa kebersamaan dan kedekatan antar sesama warga di Desa Banyu Resmi serta merupakan bentuk sosialisasi mahasiswa KKN TT kelompok 41 dan 42 terhadap warga.

b. Pembuatan Gapura Jalan

Sebagai simbol atau tanda adanya Kp. Kenanga dan penambah dekorasi dalam perayaan HUT RI ke 74 guna menambah semangat masyarakat dalam memeriahkan acara. 


\section{KESIMPULAN}

Berdasarkan program kerja yang telah dilakukan dengan pelaksanaanya selama satu bulan terhitung dari tanggal 6 Agustus 2019 sampai 5 September 2019, kami mahasiswa KKN Universitas Ibn Khaldun Bogor yang bertempat di Kp Kenanga Desa Banyu Resmi Kecamatan Cigudeg Kabupaten Bogor. Kami dapat menyimpulkan bahwa sdalam melaksanakan Kuliah Kerja Nyata (KKN) dan merealisasikan berbagai program seperti program bidang pendidikan, kesehatan, ekonomi, agama Islam dan program lainya berjalan dengan baik. Adapun pengalaman dan kondisi lapangan yang kami peroleh, dapat kami simpulkan sebagai berikut :

1. Lancarnya Program Kerja yang kita buat merupakan hasil dari kerjasama yang baik antara Masyarakat dengan Mahasiswa. Informasi yang kita dapat dari pihak Desa, Tokoh Masyarakat, dan warga sangat membantu kita selama terlaksananya kegiatan Kuliah Kerja Nyata (KKN).

2. Ilmu yang Mahasiswa punya sangat dibutuhkan oleh masyarakat yang tingkat pendidikan nya masih kurang seperti di Desa banyu Resmi karena faktor ekonomi yang tidak mendukung. Hal tersebut dilihat dari hasil survey, wawancara, dan selama merealisasikan program-program yang ada. Oleh sebab itu, dengan adanya Mahasiswa KKN TT Kelompok 41 dan 42, kita semaksimal mungkin membantu untuk memberikan ilmu dan informasi yang kita punya guna membangun kualitas hidup masyarakat di Desa Banyu Resmi dengan melakukan berbagai penyuluhan dan pengajaran.

Akses jalan yang jauh dari perkotaan merupakan hal yang baru ditemui oleh para Mahasiswa KKN TT Kelompok 41 dan 42..
Dari kegiatan KKN TT ini mahasiswa jadi bisa ikut berempati atau merasakan bagaimana menjadi warga di desa yang jauh dari kota. Selain itu Mahasiswa juga harus membantu memikirkan solusi-solusi apa yang harus dilakukan untuk memecahkan berbagai permasalahan yang ada di Desa Banyu Resmi. Hal tersebut dapat memberikan pembentukan karakter yang baru kepada para Mahasiswa yang harus menjaga tata krama, sopan santun, tutur bahasa dan mengahargai kebiasaan yang sudah ada di masyarakat Desa Banyu Resmi. Yang demikian bukan hanya semata-mata menjaga nama baik pribadi atau instansi selama kegiatan KKN TT, melainkan membentuk diri menjadi lebih baik setelah selesainya kegiatan KKN TT.

\section{Dampak Bagi Masyarakat}

Selama pelaksanaan KKN kelompok 41 dan 42 di Desa Banyu Resmi Kecamatan Cigudeg khususnya Kp Kenanga memiliki dampak yang signifikan dan dirasakan oleh masyarakat sekitar, yakni semakin terbukanya wawasan dan meningkatnya tingkat kepedulian orang tua dalam menjaga kesehatan, kebersihan dan pengasuhan anak setelah dilakukanya penyuluhan sosialisasi stunting yang merupakan masalah krusial yang dialami masyarakat saat ini. Sehingga terciptanya lingkungan yang bersih sehat, dan kondusif di wilayah Kp Kenanga. Dilihat dari segi pendidikan sendiri, masyarakat terlihat antusias dan terbantu dalam menjalankan program bantuan belajar untuk anak-anak warga Kp Kenanga baik belajar mengaji maupun bimbingan belajar lainya. Kami pun melihat adanya banyak peluang usaha yang dapat dilakukan oleh warga setelah dilakukanya beberapa penyuluhan tentang kewirausahaan, terbuktinya antusias warga 
yang tertarik dalam membuat inovasi baru merupakan dampak yang jelas terlihat.

\section{SARAN}

Berikut beberapa Saran dan yang dapat kami jabarkan selama program KKN TT 2019 yang berlangsung kurang lebih selama 30 hari di Desa Banyu Resmi Kecamatan Cigudeg

1. Pemberian dukungan moral ataupun moril yang lebih dari aparat Desa setempat.

\section{DAFTAR PUSTAKA}

Profil Desa Banyu Resmi Tahun 2017 Kecamatan Cigudeg Kabupaten Bogor. (Tidak Diterbitkan)

Fatimah, Fety., Latif, Abdul., dan Salsabila, Biella. (2018). Pengabdian Masyarakat menuju Desa Pamegarsari yang mandiri melalui peningkatan Pendidikan, 142.

Prasetya, E. (2018). Pemberdayaan Masyarakat Tentang Kesehatan, Pendidikan dan Kreatifitas. Abdi Dosen: Jurnal Pengabdian Pada Masyarakat 2 (1), 19-25.

Rachmawati, F., Widhyaestoeti, D. (2020). Early Warning System Untuk Prediksi
2. Saling bekerja samanya para pihak terkait, baik Dinas Kepemerintahan, pihak swasta, dan juga kesadaran para masyarakat sendiri.

3. Meneruskan dan menjalankan program kerja yang telah dijalankan atau terealisasi selama kegiatan KKN TT 2019 berlangsung.

Tingkat Pelayanan Jalan di Jalur SSA Kota Bogor. Krea-TIF 8 (2), 9-18

Sahril, M. (2015). The Identity of the Main Character in Life of Pi novel by Yann Martel (Psychology of Literature). ENGLISH JOURNAL 9 (1), 40-47

(2019). Petunjuk Pelaksanaan KKN Tematik Terintegrasi 2019. Bogor: LPPM UIKA

http://bogor.ac.id/index.php/ABDIDOS/iss ue/archive

http://www.sarjanaku.com/2011/09/pembe rdayaan-masyarakatpengertian.html? $\mathrm{m}=1$ 